\title{
REVIEW
}

\section{Cell kinetics and cell cycle regulation in lymphomas}

\author{
L Leoncini, S Lazzi, C Bellan, P Tosi
}

J Clin Pathol 2002;55:648-655

The proliferative indices of non-Hodgkin's lymphomas are useful prognostic indicators and provide information independent of other histological and clinical variables. However, proliferative indices alone do not suffice to characterise cell growth. A high cell production rate may be compensated, almost or fully, by a high cell deletion rate. A re-evaluation of parameters of cell kinetics in view of our increasing knowledge of the molecular pathways of cell cycle control may provide more prognostic information for the management of patients with malignant lymphomas.

See end of article for authors' affiliations

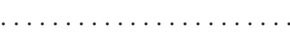

Correspondence to: Professor L Leoncini, Institute of Pathological Anatomy and Histology, University of Siena, Strada delle Scotte 6, 53100

Siena, Italy;

leoncinil@unisi.it

Accepted for publication 22 August 2001
C ontinued evolution in the classification of non-Hodgkin's lymphomas (NHLs) beyond the "working formulation" led to the development of the "revised European-American classification of lymphoid neoplasm" or the REAL classification, which was proposed by the InterWorld Health Organisation updated and revised that classification with input from additional experts to broaden the consensus and to extend the principle of disease definition. ${ }^{2}$ This classification scheme is based on morphological, immunophenotypic, and cytogenetic/molecular information. However, the REAL classification also stressed that within any disease entity a variety of prognostic factors influence the clinical outcome. Thus, the REAL classification highlighted the distinction between a disease entity and a prognostic management of patients with malignant lymphoma and leukaemia. They must provide diagnoses that are both accurate and reproducible. It is also essential that the diagnoses made have clinical relevance, providing information that is pertinent to the prognosis and treatment of haematological malignancies.

"There is now increasing evidence that cell proliferation and cell death (apoptosis) are the result of a balanced interaction among multiple regulators such as the oncogene and oncosuppressor gene products and cell cycle associated proteins"

The proliferative indices of NHLs are useful prognostic indicators and provide information independent of other histological and clinical variables. ${ }^{34}$ This pertains to mitotic indices, in addition to percentages of cells in the S, G2, and $\mathrm{M}$ phases of the cell cycle. ${ }^{5-8}$ However, proliferative indices alone do not suffice to characterise cell growth. A high cell production rate may be comnational Lymphoma Study Group in 1994. ${ }^{1}$ The factor. Pathologists play multiple roles in the pensated, almost or fully, by a high cell deletion rate. The opposite should also be considered: it has long been recognised that a progressive accumulation of long lived cells can, even at a low mitotic activity, result in a considerable growth rate. There is now increasing evidence that cell proliferation and cell death (apoptosis) are the result of a balanced interaction among multiple regulators such as the oncogene and oncosuppressor gene products and cell cycle associated proteins. $^{9-11}$ These processes are unlikely to be understood simply by analysis of in vitro systems and cell lines. Histopathologists with their knowledge of tissue architecture have much to offer to scientists who study the biochemical and molecular processes of proliferation, growth, and cell death. In histological sections, mitosis and apoptosis are the morphologically recognisable phenomena that most closely reflect cell birth and individual cell death and, thus, cell production and cell deletion in numerical terms. In addition, many of the proteins involved in cell cycle and cell death control may now be detected by monoclonal and/or polyclonal antibodies in tissue sections (fig l). ${ }^{12}$ Their evaluation in conjunction with the assessment of mitotic and apoptotic indices on biopsy material would aid in the understanding of some of the most common cell kinetic abnormalities found in malignant lymphomas. Improvements in therapeutic approaches might then be made possible through a better molecular understanding of lymphoma cell biology.

\section{CELL CYCLE REGULATION}

In mammalian cells, transition through the cell cycle is controlled at different checkpoints. Regulation is achieved through a family of serine/ threonine protein kinases, consisting of regulatory cyclin subunits that bind to and activate catalytic cyclin dependent kinases (CDKs). ${ }^{13}$

Eleven of these cyclins (A, B1, B2, C, D1, D2, D3, E, F, G, and H ), which are expressed in a cell cycle dependent manner, have been described so far.

Abbreviations: BLL, Burkitt-like lymphoma; $\mathrm{Al}$, apoptotic index; BL, Burkitt's lymphoma; eBL endemic CDK, cyclin dependent kinase; $B L B C L$, diffuse large $B$ cell lymphoma; Burkitt's lymphona; eBL, endemic Burkitt's lymphoma; EBV, Epstein-Barr virus; HRS, Hodgkin-Reed Sternberg cells; IAP, inhibitor of apoptosis protein; Ig, immunoglobulin; LMP-1, latent membrane protein $1 ; M C L$, mantle cell lymphoma; $\mathrm{MI}$, mitotic index; MPF, M phase promoting factor; NF- $\mathrm{KB}$, nuclear factor $\kappa B ; \mathrm{NHL}$, non-Hodgkin's lymphoma; NPM, nucleophosmin; $\mathrm{pRb}$, retinoblastoma protein; REAL, revised European-American classification of lymphoid neoplasm; SLVL, splenic lymphoma with villous lymphocytes; SMZL, $\mathrm{sBL}$, sporadic Burkitts lymphoma; splenic marginal zone lymphoma 

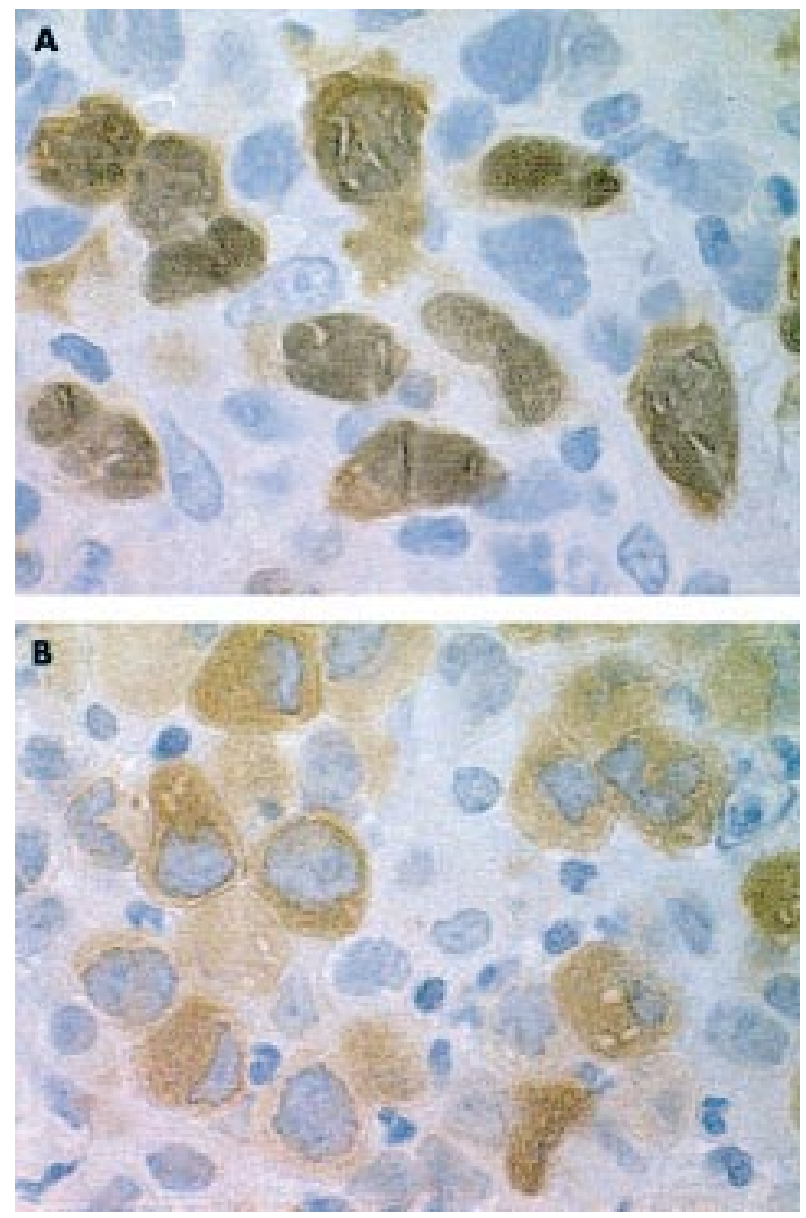

Figure 1 Immunostaining for (A) cyclin A and (B) cyclin B. Cyclin A is localised in the nucleus, whereas cyclin B shows either cytoplasmic or cytoplasmic and nuclear positivity.

Specific cyclin-CDK complexes control the cell cycle at different cell cycle checkpoints.

The cyclin-CDK complexes most closely linked to the late G1 phase checkpoint are the D-type cyclins (D1, D2, and D3) and their partners CDK4 and CDK6 (fig 2). ${ }^{11}$ The major targets of cyclin D-CDK4 and cyclin D-CDK6 complexes are the members of the retinoblastoma protein $(\mathrm{pRb})$ family, $\mathrm{pRb} /$ $\mathrm{p} 105, \mathrm{pRb} 2 / \mathrm{p} 130$, and p107. A variety of experiments have documented the role of these proteins in controlling the Gl checkpoint of the cell cycle. These proteins share considerable sequence homology and also the ability to interact with and regulate the E2F/DP family of transcription factors, generically referred to as E2F. ${ }^{11}$ Although they have similar functional properties, each protein has a different temporal profile of interaction with different E2F members. Ectopic expression in the Gl phase of cyclin Dl under the control of an inducible promoter causes early phosphorylation of $\mathrm{pRb}$ family proteins and the acceleration of the cell cycle through Gl. ${ }^{14}$

Cyclin $\mathrm{E}$ is a rate limiting component of the machinery that controls $S$ phase entry and centrosome duplication in multicellular eukaryotes. Periodic accumulation of the cyclin E-CDK2 complex during the G1 and S phases of the cell cycle is achieved in part by E2F dependent transactivation of the cyclin E gene ${ }^{15}$ and by ubiquitin mediated destruction. ${ }^{16}{ }^{17}$ Once the cell enters S phase, cyclin E is degraded rapidly and the activation of CDK2 is taken over by cyclin A. The concentration of cyclin A increases gradually during the later stages of $\mathrm{Gl}$ and some binding with CDK2 is a prerequisite for entry into $\mathrm{S}$ phase, during which cyclin A forms a complex with
CDK2 and p107. This complex has an important role in both the initiation and maintenance of DNA synthesis. It activates the proteins at the DNA replication origins that initiate DNA synthesis at different sites or origins on the chromatids. ${ }^{18}$ The activation of CDK2 by cyclin A is necessary for the continuation of $\mathrm{S}$ phase, but towards the end of this phase cyclin A starts to activate another kinase, CDKl/p34 (Cdc2), in preference to CDK2. This signals the completion of the S phase and the onset of another gap phase, G2. ${ }^{11}$ Upon the completion of the $\mathrm{S}$ phase, the G2 phase provides a break between the fundamental procedures of DNA synthesis and mitotic division. During this gap the cell can ensure that DNA replication is both complete and accurate.

The activation of CDKs is regulated by additional mechanisms, which include CDK inhibitors and phosphorylation. Seven mammalian CDK inhibitor genes have been identified thus far and belong to two separate families, the INK4 and the CIPl/KIPI family. These genes are responsible for integrating many growth inhibitory pathways, including responses to DNA damage, senescence, and contact inhibition. ${ }^{19}$ The INK4 family includes four closely related ankyrin repeat containing genes: pl6 (INK4a), pl5 (INK4b), pl8 (INK4C), and pl9 (INK4d). INK4 proteins bind to CDK4 or CDK6 and prevent D-type cyclin binding and activation. Both pl5 and pl6 are recognised as tumour suppressors that are regulated by the pRb family. The CIP/KIP family contains three genes: p2l (CIP1/WAF1), p27 (KIP1), and p57 (KIP2). p21, p27, and p57 regulate multiple CDK enzymes, including CDK4/6-cyclin D, by forming ternary complexes with CDK and cyclin proteins. Recent evidence points to a role for p27 (KIP1) in the activation of CDK4/6-cyclin D complexes and the inhibition of CDK2-cyclin E. ${ }^{19}$

p53 is also involved in the control of cell cycle checkpoints. p53 protects cells from neoplasia by inducing apoptosis, DNA repair, and cell cycle arrest in response to a variety of stresses. ${ }^{20} \mathrm{p} 53$ dependent arrest of cells in the Gl phase of the cell cycle is an important component of the cellular response to stress. Recent evidence suggests that p53 is implicated in controlling entry into mitosis when cells enter G2 with damaged DNA or when they are arrested in S phase as a result of depletion of the substrates required for DNA synthesis. Part of the mechanism by which p53 blocks cells at the $\mathrm{G} 2$ checkpoint involves the inhibition of CDKl/p34, the cyclin-dependent kinase required for entry into mitosis. ${ }^{21}$

A more detailed description of cell cycle machinery would be beyond the aim of our present review. However, we would like to point out that any alteration of this complex system can result in uncontrolled cell proliferation with different proliferative patterns. Many disturbances of molecular mechanisms underlying cell cycle control have been detected in malignant lymphomas.

1 lq13 translocations with resultant bcl-1 rearrangement are a characteristic feature of mantle cell lymphoma (MCL) ${ }^{22}$ This alteration leads to the constant overexpression of cyclin $\mathrm{D} 1,{ }^{23}$ which is not normally expressed in lymphocytes. This results in deregulation of cell cycle control by overcoming the suppressor effect of pRb and p27 (KIPl). ${ }^{24}$ It should be mentioned that lymphoma cell lines harbouring the tl $1 ; 14$ translocation show cyclin Dl protein but no or very low amounts of cyclin D3; in contrast, other B cell lines, T cell lines, and peripheral blood lymphocytes strongly express cyclin D3 and react negatively for cyclin Dl, suggesting that chromosomal translocation 11;14 leads to an abnormal expression of cyclin Dl in the tumour cells of MCL and induces consecutive downregulation of cyclin D3. ${ }^{25}$ However, cyclin D1 overexpression is not restricted to $\mathrm{B}$ cell proliferation with a distinct proliferative capacity, or to the $\mathrm{t}(11 ; 14)$ translocation, and cyclin Dl is involved in the physiopathology of other lymphoma types. ${ }^{26}$ Aggressive variants of MCL have additional genetic alterations, including inactivation of the $\mathrm{p} 53$ and pl6 (INK4a) tumour suppressor genes. The deletion of pl6 (INK4a) occurs 


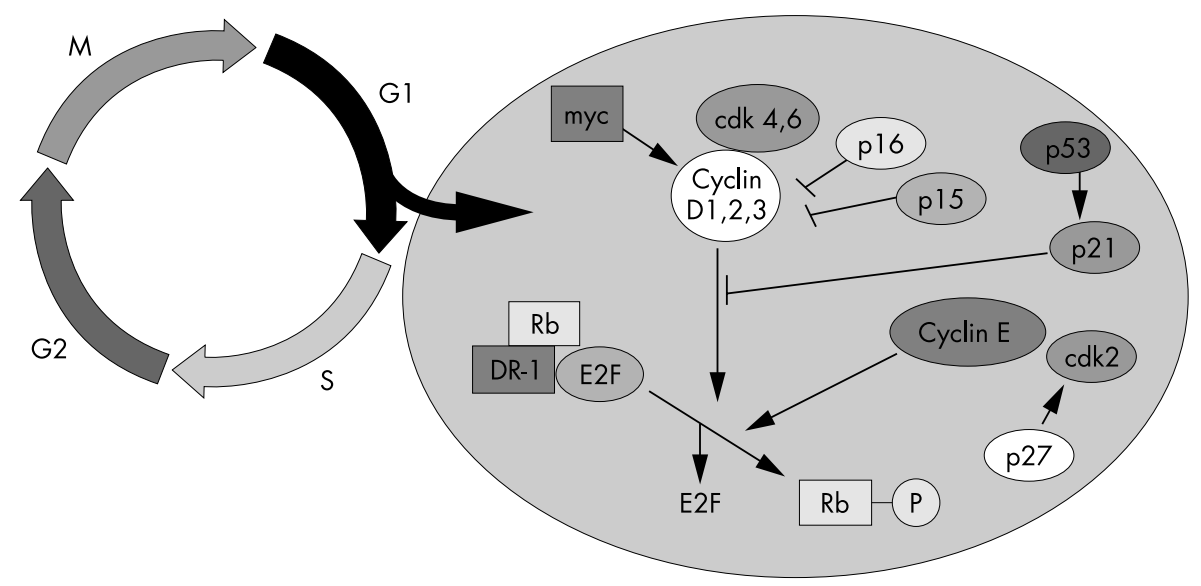

Figure 2 Schematic representation of a molecular networking model for cell cycle regulation of the $\mathrm{Gl}$ phase.

in approximately one half of MCLs and is a more relevant indicator of the proliferative features than morphological criteria. $^{27}$

The 7;14 translocation, originally found in a case of chronic lymphocytic leukemia, involves the juxtaposition of the immunoglobulin (Ig) locus to a human retroviral sequence of the transposable-like human element family. ${ }^{28}$ Further studies have found that deletions and translocations of chromosome $7 \mathrm{q}$ are the most common cytogenetic abnormalities found in splenic lymphoma with villous lymphocytes (SLVL), a leukaemic variant of splenic marginal zone lymphoma (SMZL), with the q21-q22 region being most frequently affected. The cloning of the breakpoint at 7q21 in SLVL revealed that it was located within a small region of DNA $3.6 \mathrm{~kb}$ upstream of the transcription start site of the CDK6 gene ${ }^{29}$ which promotes Gl to $\mathrm{S}$ phase transition. ${ }^{30}$ Thus, dysregulation of CDK6 gene expression probably contributes to the pathogenesis of SLVL and SMZL.

\section{"11q13 translocations with resultant bcl-1 rearrangement are a characteristic feature of mantle cell lymphoma"}

Several studies have reported mutations of the p53 gene and/or abnormal expression of the $\mathrm{p} 53$ protein in a substantial number of patients with follicular lymphomas. ${ }^{31}$ In particular, alteration of $\mathrm{p} 53$ has been suggested to play a role in the transformation of follicular lymphoma into diffuse large B cell lymphoma (DLBCL).

Yet, the pRb and p53 pathways are both important in the development of de novo DLBCL. ${ }^{32}$ DLBCLs are also frequently associated with reciprocal translocations involving the chromosomal band 3q27 and either one of the Ig genes or another partner chromosome. ${ }^{33}$ Cloning of the 3;4 translocation allowed the identification of Bcl-6, a zinc-finger transcription factor. ${ }^{34}{ }^{35}$ Gene inactivation studies have shown that Bcl-6 plays a key role in the activation and proliferation of B cells within the germinal centre. ${ }^{36}$ Overexpression of the gene results in apoptosis and delays S phase progression. ${ }^{37}$ However, it remains unclear how Bcl-6 overexpression leads to transformation. No mouse transgenic models for Bcl-6 have been reported to date.

p27 (KIPl) expression in DLBCLs with adverse clinical significance has been reported. ${ }^{38}$ This suggests that the anomalous p27 (KIPl) protein may be rendered non-functional through interaction with other cell cycle regulator proteins. Evidence in favour of p27 (KIP1) sequestration by cyclin D3 was provided by coimmunoprecipitation studies in a Burkitt's lymphoma (BL) cell line (Raji), which showed the existence of cyclin D3-p27 (KIP1) complexes and the absence of CDK2p27 (KIP1) complexes. ${ }^{39}$ These results support the hypothesis that there are cyclin D3-p27 (KIP1) complexes in a subset of aggressive B cell lymphomas in which p27 (KIP1) lacks the inhibitory activity found when it is bound to cyclin E-CDK2 complexes. A recent study indicates that p14 (ARF) alterations occur in a subset of aggressive NHLs, but that they are always associated with pl6 (INK4a) aberrations. ${ }^{40}{ }^{41}$ Thus, the concomitant disruption of pl6 (INK4a) and pl4 (ARF)-p53 regulatory pathways may have a cooperative effect in the progression of these tumours. ${ }^{42-44}$ Therefore, it is possible to identify several distinct molecular types of DLBCL, corroborating the hypothesis that the heterogeneity of the disease relies on its pathogenetic heterogeneity. ${ }^{45}$

BL is characterised by an 8;14 translocation, which juxtaposes c-myc to the heterogenous regulatory elements derived from the Ig loci. ${ }^{46}$ As a consequence, in BL, c-myc is consistently found to be transcriptionally activated. ${ }^{46}$ The mechanisms by which c-myc promotes cell cycle progression in B cells are not known completely. Several lines of experimental evidence show that the deregulated expression of c-myc can influence the growth of B cells in vitro and in vivo. Myc is required for progression through the cell cycle, and normally its expression correlates tightly with the proliferative state of the cell. The functions of myc in this regard have been recently reviewed. ${ }^{47}$ Myc null cell lines are characterised by a profound growth defect as a result of lengthening of both the G1 and G2 phases of the cell cycle. The largest defect observed in these cells is a 12 fold reduction in cyclin D1-CDK4 and D1-CDK6 complexes during the G1 to S phase transition. However, the activity of other cyclin-CDK complexes, including cyclin E-CDK2 and cyclin A-CDK2, is also diminished, and the growth rate is not restored by overexpression of these cyclins. ${ }^{47}$ These findings are explained by the knowledge that Myc directly induces the expression of cyclins D1 and D2, which, as cyclin-CDK complexes, sequester the cell cycle inhibitors p27 (KIPl) and p21 (CIPl/WAFl), thereby releasing cells from inhibition of the cell cycle. ${ }^{48}{ }^{49}$ This is at least one of the pathways by which Myc exerts its proliferative effects. Oncogenic conversion of c-Myc is also believed to stem from amino acid substitutions in c-Myc exon 2, which affect the $\mathrm{N}$-terminal transcriptional activation domain. ${ }^{50}$ These mutations, which are found in comparable positions in retroviral $\mathrm{v}$-Myc, occur in more than $50 \%$ of BLs and cluster in hot spots. ${ }^{52}$ The high prevalence of these mutations suggests that they play a biological role in lymphomagenesis because, in normal conditions, the activity of the c-Myc transactivation domain is suppressed by protein-protein interactions, including interactions with the pRb related family proteins. ${ }^{5354}$ In addition, c-myc alteration is not the only genetic lesion found in BL. Cooperating alterations of other cell cycle associated genes probably contribute to the pathogenesis of BL. p53 mutations have been found in $30-40 \%$ of BL samples. ${ }^{55}$ Genetic disturbances in the nuclear localisation signal of the 


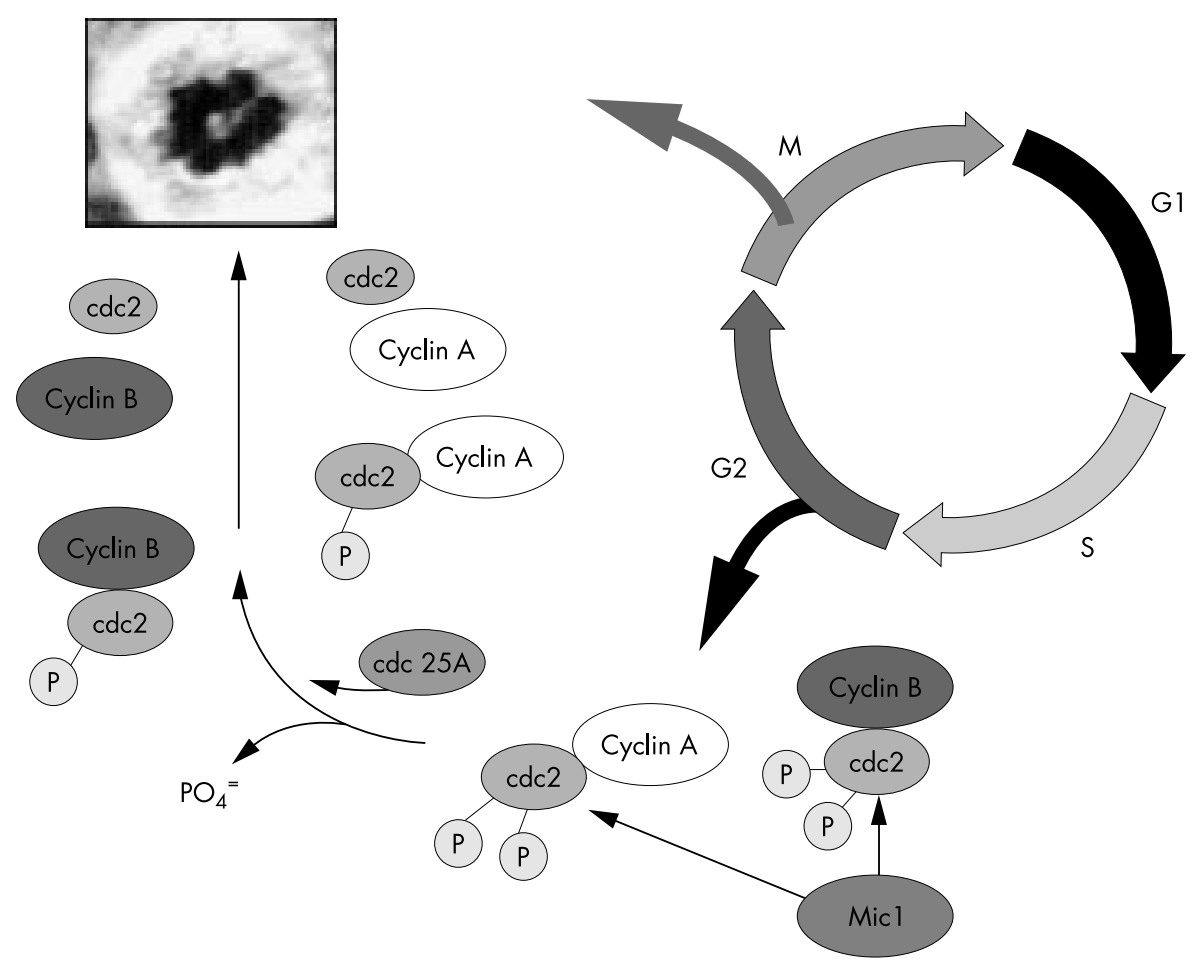

Figure 3 Schematic representation of a molecular networking model for cell cycle regulation of the $\mathrm{G} 2-\mathrm{M}$ phase.

$\mathrm{Rb}$ related gene $\mathrm{Rb} 2 / \mathrm{p} 130$ have recently been documented in BL cell lines, in addition to primary tumours. ${ }^{56}$ These mutations may impair the ability of the respective gene product to function as a growth suppressor nuclear protein, pRb2/ pl30 being exclusively cytoplasmic. ${ }^{57}$ Increased cell proliferation caused by alteration of the control mechanism by $\mathrm{pRb}$ related proteins may represent a first step in lymphomagenesis in BL, because it has been shown that increased cell proliferation is sufficient to account entirely for tumour prevalence. ${ }^{589}$ Additional genetic changes may occur subsequently, and misense mutations of c-myc may be selected during lymphomagenesis.

Finally, the evaluation of cell cycle associated proteins in various types of NHL can distinguish groups of lymphomas with unequal growth characteristics.$^{60}$ In addition, a recent study suggests that cyclin D3 is expressed differentially among lymphoma subtypes and that overexpression might identify a subpopulation of patients with adverse clinical features and poor outcome. ${ }^{61}$ The expression of p27(KIP1), pRb, and the cell proliferation marker Ki-67 (MIB-1) has also been evaluated in another study, which showed coordinate changes in the expression of p27 (KIPl) and pRb in NHLs. ${ }^{62}$ This suggests that changes in the control of the cell cycle are closely related to the pathobiology of NHL. Furthermore, a distinct pattern of pRb2/p130 and p107 expression in a large cohort of patients with NHL indicates the possibility of different pathogenetic mechanisms within and among lymphoma subtypes. ${ }^{63}$ All these findings support the REAL classification recommendation to examine each disease entity with respect to possibly divergent molecular features, growth patterns, and clinical aggressiveness. ${ }^{1}$

\section{MITOSIS}

Mitosis is the process by which eukaryotic cells ensure the equal partition of their chromosomes at cell division. The key events of mitosis are: (1) prophase-the condensation of the duplicate chromosomes from a dispersed and metabolically active state to a compacted condition, suitable for transport; (2) prometaphase-the positioning of the condensed chromosomes, first by orientation so that one copy of each chromosome addresses one end of the cell and then by the motion of each chromosome to the midplane of the cell to form the "metaphase plate"; (3) anaphase-the separation of each chromosome into two identical parts, followed by their movement toward the opposite ends of the cell; and (4) telophase-the re-formation of nuclei and the decondensation of the chromosomes to re-establish the interphase condition.

"The mitotic activity of malignant lymphomas is a useful prognostic parameter, and mitotic indices in conjunction with apoptotic indices allow an estimation of neoplastic growth"

For some time it has been known that a specific protein (or group of proteins) is involved in the signal to initiate the onset of mitosis (fig 3 ). This protein was initially known as maturation promoting factor but is now called $\mathrm{M}$ phase promoting factor (MPF). MPF consists of cdc2/p34 and its activating mitotic cyclins, cyclins A or B. Although it appears that cyclin $\mathrm{A}-\mathrm{CDKl} / \mathrm{p} 34$ has a more important role in the completion of $\mathrm{S}$ phase and the preparation for mitosis, cyclin B-CDKl/p34 controls the onset, sequence of events, and the completion of mitosis. In short, the $\mathrm{G}_{2}-\mathrm{M}$ transition of the cell cycle is triggered by CDKl/p34 when it associates with cyclin Bl to form the MPF. In contrast to $\mathrm{CDKl} / \mathrm{p} 34$, which is usually present throughout the cell cycle in proliferating cells, cyclin Bl remains virtually undetectable during the G0/Gl and most of the $\mathrm{S}$ phase but accumulates in the $\mathrm{G} 2$ phase. This process, which parallels the phosphorylation of cyclin $\mathrm{Bl}$ and dephosphorylation of $\mathrm{CDKl} / \mathrm{p} 34,{ }^{64}$ may exhibit wide intercellular variations. ${ }^{65}$ The full biological activity of MPF is achieved with the nuclear localisation of this complex, ${ }^{66}$ and is maintained up to the metaphase-anaphase transition in mitosis. At that time, ubiquination and degradation of cyclin Bl sets in, as a result of the catalytic activity of the metaphase-anaphase promoting complex. ${ }^{67}$ The machinery driving a cell through mitosis may be counterbalanced by inhibitors, such as the cyclin dependent kinase inhibitor $\mathrm{p} 2 \mathrm{l}$, which remain under the control of $\mathrm{p} 53 .{ }^{68}$ 
In histological sections, mitosis is the morphologically recognisable phenomenon that most closely reflects cell birth and, thus, cell production in numerical terms. The clinical relevance of mitotic indices (MIs) resides, of course, in the theoretical possibility of estimating real tumour growth, which equals cell production minus cell death (apoptosis). To attain this goal, the time required for mitosis (mitotic time) and for the apoptotic process (apoptotic time) should be known. However, the present knowledge on mitotic time and apoptotic time in vivo of human lymphoid neoplasia is limited. Nevertheless, the mitotic activity of malignant lymphomas is a useful prognostic parameter, ${ }^{5-7}$ and MIs in conjunction with apoptotic indices allow an estimation of neoplastic growth. ${ }^{69}$

It should be emphasised that the entry of a cell into the cell cycle and mitosis is not necessarily an indication that the respective cell will successfully terminate the cell cycle and divide. One example of this is the occurrence of abortive mitosis in the Hodgkin-Reed Sternberg cells (HRS) of Hodgkin's disease. ${ }^{70}$ HRS cells express proliferation associated antigens in the absence of normal progression through mitosis. ${ }^{71-73}$ This is correlated with the finding of an unusually low proportion of HRS cells expressing cyclin B in the cytoplasm and in the nucleus, suggesting a derangement of MPF kinetics and functions. ${ }^{74}$ In contrast, an overexpression of cyclin B has been observed in anaplastic large cell lymphoma, which is associated with the positivity of neoplastic cells for ALK-c and thus the $t(2 ; 5)$ translocation..$^{75}$ The molecular background of the intense mitotic activity in ALK positive anaplastic large cell lymphoma has not yet been fully clarified. ALK, a novel receptor that is closely related to leucocyte tyrosine kinases, is expressed by certain cells of the nervous system but not by the normal lymphoid tissue. ${ }^{76}$ The $t(2 ; 5)$ translocation brings the part of the gene that encodes the intracellular portion of ALK under the control of the strong NPM (nucleophosmin) gene promoter, leading to its ectopic expression in lymphoid cells and the resultant dysregulated growth. ${ }^{78}$ The NPM portion of the fusion protein provides an oligomerisation motif that promotes a self association of NPM-ALK and results in its constitutive activation. ${ }^{79}{ }^{80}$ Several tyrosine kinase signalling substrates are known to interact with NPM-ALK and may be involved in transformation mediated by the protein. Among these, phospholipase $\mathrm{C} \gamma$ appears to be important for the mitogenic signal mediated by NPM-ALK. ${ }^{81}$ This is in line with experimental findings suggesting that the expression of cDNA encoding NPM-ALK in rat la fibroblasts induced accelerated cell cycle entry and pronounced upregulation of cell cycle associated proteins. ${ }^{82}$

\section{APOPTOSIS}

The process of apoptosis is classically defined by morphological changes that lead to characteristic alterations in cellular and subcellular structure, including cell shrinkage, nuclear fragmentation, and chromatin condensation. The apoptotic process is carefully regulated through a network of positive and negative elements. However, all pathways culminate with an enzymatic cascade that involves a series of self activating proteases known as caspases. The induction of apoptosis via the caspase cascade appears to occur through at least two separate, parallel pathways. One of these is dependent on mitochondria and is modulated by the release of proapoptotic proteins from these organelles into the cytosol. The other major pathway involves caspase activation via membrane receptors in response to extracellular ligands. Thus, this second apoptosis pathway is commonly referred to as the extrinsic pathway. The best examples of extrinsic pathway stimuli are members of the tumour necrosis factor (TNF) family of cell death receptors. All apoptosis pathways are tightly regulated, probably involving hundreds of genes acting either to enhance or to inhibit caspase activation.
In tissue with the capacity of self renewal, apoptosis is as important as cell proliferation in determining the size of the cell population. Given its contribution to cell turnover in physiological and pathological conditions, it is important to be able to identify and quantify the process of apoptosis in cells and tissues. Although historically morphological methods have been favoured, the recognition that apoptosis is associated with the cleavage of DNA between nucleosomes has been regarded as a key parameter, and methods that take advantage of this characteristic have been developed. These methods have been used to identify apoptotic bodies in tissue sections. ${ }^{83}$ Apoptotic indices (AIs) can distinguish higher from lower grade NHLs and diffuse large cell NHLs have AIs similar to working formulation high grade NHLs. ${ }^{84}{ }^{85}$ In particular, it has been shown that AIs correlate positively with proliferative indices in malignant lymphomas of different histotypes. ${ }^{84}$ However, this does not mean that the two parameters are mutually replaceable; rather, they define different kinetic features of a neoplastic cell line that may complement each other. Considerable exponential growth of a cell population may be based on the predominance of cell proliferation, possibly with a substantial AI, or on the accumulation of long lived cells. ${ }^{86}$ The decision for a cell either to proceed into the cell cycle or to undergo apoptosis is made at a certain metabolic checkpoint, which regulates these processes depending on the signal received. ${ }^{87}$

\section{"All apoptosis pathways are tightly regulated, probably involving hundreds of genes acting either to enhance or inhibit caspase activation"}

The Bcl-2 proteins are central modulators of apoptosis that operate predominantly within the mitochondrial pathway. We know that Bcl-2 related proteins either suppress or promote apoptosis by interacting with and functionally antagonising each other. Whereas the expression of some, such as Bcl-2 and Bcl-xL, suppresses apoptosis, the expression of others, such as Bax and Bak, promotes apoptosis. ${ }^{88}{ }^{89}$ The balance between viability and apoptosis depends on the ratio of Bcl-2 homodimers and heterodimers and Bax or Bax related dimers. ${ }^{90}{ }^{91}$ These interactions either prevent caspase activation in the case of apoptosis inhibition, or promote caspase activation in the case of apoptosis induction. Imbalances in the ratio of Bcl-2 to Bax can lead to a resistance to sensitisation to cell death stimuli. A classic example of this is seen in follicular lymphoma, where the $t 14 ; 18$ translocation results in the overexpression of Bcl-2 and consequent inhibition of apoptosis. In an attempt to clarify the role of the apoptosis counteracting protein Bcl-2 in NHL, across the boundaries of histological classification, a highly significant inverse relation ("mirror image") between the proportion of Bcl-2 positive cells and AI was shown in each case. ${ }^{92}$ Thus, it is conceivable that the Bcl-2 protein may be a major regulatory factor counteracting programmed cell death in these tumours, independently from the $14 ; 18$ translocation. The frequent presence of the Bcl-2 protein in indolent NHL is in line with the often long standing, indolent course of these neoplasms, in which progressive accumulation of long lived cells protected against apoptosis is the major background of an increasing tumour cell mass, rather than pronounced proliferative activity. More recent data suggest that in addition to the known overexpression of cyclin D1, which drives entry into the cell cycle, disturbances of pathways associated with apoptosis contribute to the development of MCL. ${ }^{93}$ Furthermore, two separate groups of aggressive NHL, one with rather high AI values and low percentages of $\mathrm{Bcl}-2$ positive cells and the other with the reverse characteristics have been detected..$^{92}$ The coexistence of high percentages of Bcl-2 positive cells and raised AIs in several aggressive NHLs may tentatively be explained by Bcl-2 independent pathways to programmed cell death. ${ }^{92}$ Certain 
other genes, such as c-myc, p53, and pRb, are also involved in the network controlling cell proliferation and apoptosis. ${ }^{11}$ Lasting disturbances of this complex system through mutation with excessive activation of oncogenes or loss of function of tumour suppressor genes, for instance, can lead to an unbalanced selective survival advantage of the respective cell lines.

Death receptors belonging to the TNF family of receptors are capable of inducing apoptosis through mechanisms that are independent of the mitochondrial pathway. The Fas and TNF- $\alpha$ signal transduction pathways directly regulate caspase activation through recruitment of adapter molecules to the cytoplasmic domain of the receptor. ${ }^{94}$ Resistance to Fas mediated death may be an important factor in B cell transformation in vivo. Many lymphomas are insensitive to Fas mediated death signals, although all can form a death inducing signalling complex. Additional studies suggest that some lymphomas can be blocked at the death inducing signalling complex by antiapoptotic proteins, whereas others are inhibited downstream of caspase 8 activation. ${ }^{95}$ Anti-Ig treatment of a Fas sensitive line, A20.2J, activated several genes whose products may block apoptosis proximally (such as FLICE inhibitory protein) or at late points (such as Bcl-2 family members)..$^{96}$

\section{"The balance between viability and apoptosis depends on the ratio of $\mathrm{Bcl}-2$ homodimers and heterodimers and Bax or Bax related dimers"}

The nuclear factor $\mathrm{\kappa B}(\mathrm{NF}-\mathrm{\kappa B})$ proteins are key regulators of differentiation and survival in B cells. The induction of NF- $\mathrm{KB}$ activity protects cells from apoptosis induced by a variety of stimuli, including exposure to TNF- $\alpha$, chemotherapy, and ionising radiation. NF- $\mathrm{KB}$ controls a signalling network in HRS cells, which promotes tumour cell growth and confers resistance to apoptosis. ${ }^{98}$ Recent studies have elucidated some mechanisms by which NF- $\mathrm{KB}$ inhibits apoptosis, such as the induction of inhibitor of apoptosis proteins (IAP1, IAP2) in malignant lymphomas. ${ }^{99}$

The IAPs represent another family of proteins that serve to suppress caspases. So far, six members of the IAP family have been identified in humans, including XIAP, cIAP1, CIAP2, NAIP, and survivin. Several IAPs have been shown to inhibit apoptosis by directly binding to effector caspases, particularly caspases 3 and 7 . There is evidence that implicates the overexpression of IAPs as a cause of apoptosis dysregulation in cancer cells. For example, cIAP2 is known to undergo chromosomal translocations and is activated in certain types of lymphoma, particularly those arising in mucosal tissue (MALTomas). ${ }^{100}$ In addition, survivin is inappropriately expressed in a variety of cancers, including high grade lymphomas. ${ }^{101}$

The relation between different types of virus infection, disease, and the viral strategy for normal persistence in humans is now beginning to be understood. The ability of Epstein-Barr virus (EBV) to modulate cell growth and death is central to these processes. ${ }^{102}$ There is strong evidence that endemic BLs (eBLs) and Burkitt-like lymphomas (BLLs) grow much faster than sporadic BLs (sBLs), as shown by differences in mitotic and apoptotic indices. ${ }^{102}$ EBV seems to play a noticeable role in the pathogenesis of eBL, but not (or less so) in the development of sBL and BLL. Yet, EBV positive BL has been associated with distinctly lower AIs and smaller median percentages of Bcl-6 positive cells than EBV negative tumours. The role of latent membrane protein 1 (LMP-1), an EBV product found in latency types II and III, in the pathogenesis of BL remains undetermined. In certain human BL cell lines, LMP-1, in conjunction with the EBV encoded nuclear antigen 2 , acts as a potent gene transactivator and may favour uncontrolled proliferation. Conversely, LMP-1 upregulates bcl-2 protooncogene expression and thus counteracts apoptosis.

\section{Take home messages}

- The proliferative indices of non-Hodgkin's lymphomas (NHLs) are informative independent prognostic indicators, although the balance between cell death (apoptosis) and cell proliferation is the most important factor determining overall tumour growth

- This balance involves the interactions of multiple regulators such as the oncogene and oncosuppressor gene products and cell cycle associated proteins and our increasing knowledge of the molecular pathways of cell cycle control may provide more prognostic information for the management of patients with malignant lymphomas

- Gene mutations or translocations involving cell cycle regulators, such as the cyclin dependent kinases (CDKs) and their inhibitors, the cyclins, and p53, have been implicated in many lymphomas - for example, p53 mutations in diffuse large B cell lymphoma

- All apoptotic pathways culminate with an enzymatic cascade that involves a series of self activating proteases known as caspases. The Bcl related proteins are important regulators of apoptosis, suppressing or promoting apoptosis by interacting with and functionally antagonising each other, and disturbances in these pathways have been identified in several lymphomas

- Other factors involved in the complex pathways that control apoptosis include the tumour necrosis factor family of signal transducers, Fas, NF- $\mathrm{KB}$, and the inhibitor of apoptosis proteins and dysregulation of all these proteins has been detected in certain types of tumour

- Thus, the proper therapeutic approach should be based on detailed knowledge of the kinetic and molecular characteristics of individual tumours. In the future, genetic treatments may be devised to introduce DNA fragments into the genome of neoplastic cells so that apoptosis can be induced, and functions that have been lost could be reintroduced in the transformed cells

However, LMP is expressed in very few cases of BL. ${ }^{103}$ Viral proteins other than LMP may thus provide resistance to apoptosis in BL. It has recently been shown that ectopic expression of Bfl-1 in an EBV positive cell line, exhibiting a latency type I infection, protects against apoptosis induced by growth factor deprivation, thereby providing a functional role for Bfl-1 in this cellular context and adding Bfl-l to the list of antiapoptotic proteins whose expression is modulated by EBV. $^{104} 105$

\section{CONCLUSIONS}

Finally, we would like to make some comments on possible therapeutic implications of the data illustrated above because the proper therapeutic approach should be based on detailed knowledge of the kinetic and molecular characteristics of each tumour. Lymphomas are highly chemosensitive tumours and are often curable; however, a variable proportion of patients do not respond to treatment and run a poor clinical course. Up to now, the therapeutic approach has been based mainly on such parameters as histotype, stage, age, performance state, lactate dehydrogenase, and clinical symptoms, although none of these is useful in predicting the response to treatment in a particular patient. The study of mechanisms that regulate cell proliferation and death will be very important in determining therapeutic strategies different from the current ones.

Chemotherapy, in fact, is not specific, whereas other treatments, such as genetic ones, can lead to the introduction of DNA fragments into the genome of neoplastic cells. ${ }^{106}$ In this way, apoptosis can be induced, and functions that were lost can be reintroduced in the transformed cells.

Authors' affiliations

L Leoncini, S Lazzi, C Bellan, P Tosi, Institute of Pathological Anatomy and Histology, University of Siena, 53100 Siena, Italy 


\section{REFERENCES}

1 Harris NL, Jaffe ES, Stein $H$, et al. A revised European-American classification of lymphoid neoplasms: a proposal from the international lymphoma study group. Blood 1994;5:1361-92.

2 Harris NL, Jaffe ES, Diebold J, et al. The World Health Organization classification of neoplastic diseases of the haematopoietic and lymphoid tissues: report of the clinical advisory committee meeting, Airlie House, Virginia, November 1997. Histopathology 2000;36:69-86.

3 Weiss LM Strickler JG, Medeiros L, et al. Proliferative rates of non-Hodgkin's lymphomas as assessed by Ki-67 antibody. Hum Pathol 1987; 18:1155-9.

4 Hall PA, Levison DA, Woods AL, et al. Proliferating cell nuclear antigen (PCNA) immunolocalizaton in paraffin section: an index of cell proliferation with evidence of deregulated expression in some neoplasms. J Pathol 1990;162:285-94.

5 Brandt L, Johnson A, Olsson $\mathrm{H}$, et al. Mitotic activity and survival in advanced non-Hodgkin's lymphoma of unfavourable histology. Eur $J$ Cancer 1990;26:227-30.

6 Woods AL, Hall PA, Shepherd NA, et al. The assessment of proliferating cell nuclear antigen (PCNA) immunostaining in primary gastrointestinal lymphomas and its relationship to histological grade, $S+G_{2}+M$ phase fraction (flow cytometric analysis) and prognosis. Histopathology 1991;19:21-7.

7 Holte H, Suo Z, Smeland EB, et al. Prognostic value of lymphoma-specific S-phase fraction compared with that of other cell proliferation markers. Acta Oncol 1999;38:495-503.

8 Crocker J. Proliferation indices in malignant lymphomas. Clin Exp Immunol 1989;77:299-308

9 Renan MJ. How many mutations are required for tumorigenesis? Implications from human cancer data. Mol Carcinog 1993;7:139-46.

10 Kinzler KW, Vogelstein B. Landscaping the cancer terrain. Science 1998;280: 1036-7

11 Stein GS, Baserga R, Giordano A, et al. The molecular basis of cell cycle and growth control. New York: Wiley-Liss, 1999.

12 Tosi $\mathbf{P}$, Leoncini L. La cinetica cellulare per una classificazione bilogica dei linfomi. Pathologica 1999;91:155-61.

13 Siebert R, Willers CP, Opalka B. Role of the cyclin-dependent kinase 4 and 6 inhibitor gene family p15, p16, p18 and p19 in leukemia and lymphoma. Leuk Lymphoma 1996;23:505-20.

14 Jiang W, Kahn SM, Zhou P, et al. Overexpression of cyclin D1 in rat fibroblasts causes abnormalities in growth control, cell cycle progression and gene expression. Oncogene 1993;8:3447-57.

15 Dyson N. The regulation of E2F by pRb family-proteins. Genes Dev 1998;12:2245-62

16 Clurman BE, Sheaff RJ, Thress K, et al. Turnover of cyclin E by the ubiquitin-proteosome pathway is regulated by cdk2 binding and cyclin phosphorylation. Genes Dev 1996;10:1979-90.

17 Won KA, Reed SI. Activation of cyclin E/CDK2 is coupled to site-specific autophosphorylation and ubiquitin-dependent degradation of cyclin $\mathrm{E}$. EMBO J 1996;15:4182-93.

18 Stillman B. Cell cycle control of DNA replication. Science 1996;274: 1659-64

19 Sherr CJ, Roberts JM. CDK inhibitors: positive and negative regulators of $\mathrm{G}_{1}$-phase progression. Genes Dev 1999;13:1501-12

20 EI-Deiry WS, Harper JW, O'Connor PM, et al. WAFI CIP1 is induced in p53-mediated G1 arrest and apoptosis. Cancer Res 1994;54:1169-74.

21 Taylor WR, Stark GR. Regulation of the G2/M transition by p53. Oncogene $2001 ; 20: 1803-15$

22 Komatsu $\mathbf{H}$, Yoshida K, Seto $M$, et al. Overexpression of PRAD1 in a mantle zone lymphoma patient with a $+(11 ; 12)(q 13 ; q 11)$ translocation. Br J Haematol 1993;85:427-9.

23 Jares $\mathbf{P}$, Campo $E$, Pinyol $M$, et al. Expression of retinoblastoma gene product (pRb) in mantle cell lymphomas. Correlation with cyclin D1 (PRADI /CCND1) mRNA levels and proliferative activity. Am J Pathol 1996;148: 1591-600.

24 Quintanilla-Martinez L, Thieblemont C, Fend F, et al. Mantle cell lymphomas lack expression of $27 \mathrm{Kipl}$, a cyclin-dependent kinase inhibitor. Am J Pathol 1998;153:175-82.

25 Ott MM, Bartkova J, Bartec J, et al. Cyclin D1 expression in mantle cell lymphoma is accompanied by downregulation of cyclin D3 and is not related to the proliferative activity. Blood 1997;90:3154-9.

26 Sola B, Salaun V, Ballet JJ, et al. Transcriptional and post-transcriptional mechanisms induce cyclin-D1 over-expression in B-chronic lymphoproliferative disorders. Int J Cancer 1999:83:230-4.

27 Pinyol M, Hernandez L, Cazorla M, et al. Deletion and loss of expression of p16INK4a and p21 Wafl genes are associated with aggressive variants of mantle cell lymphoma. Blood 1997;89:272-80.

28 Wahbi K, Hayette S, Callanan M, et al. Involvement of a human endogenous retroviral sequence (THE-7) in a $t(7 ; 14)(q 21 ; q 32)$ chromosomal translocation associated with a B-cell chronic lymphocytic leukemia. Leukemia 1997;11:1214-19.

29 Corcoran MM, Mould SJ, Orchard JA, et al. Dysregulation of cyclin dependent kinase 6 expression in splenic marginal zone lymphoma through chromosome 7q translocations. Oncogene 1999;18:6271-7.

30 Sherr CJ. Mammalian G1 cyclins. Cell 1993;73:1059-65.

31 Nguyen LP, Zukerberg LR, Benedict WF, et al. Immunohistochemical detection of $\mathrm{p} 53, \mathrm{bcl}-2$, and retinoblastoma proteins in follicular lymphoma. Am J Clin Pathol 1996; 105:538-43.

32 Moller MB, Kania PW, Ino Y, et al. Frequent disruption of the RB 1 pathway in diffuse large $B$ cell lymphoma: prognostic significance of E2F-1 and p16INK4A. Leukemia 2000;14:898-904.
33 Bastard C, Tilly H, Lenormand B, et al. Translocations involving band $3 q 27$ and Ig gene regions in non-Hodgkin's lymphoma. Blood 1992;79:2527-31

34 Kerckaert J-P, Deweindt C, Tilly H, et al. LAZ3, a novel zinc-finger encoding gene, is disrupted by recurring chromosome $3 q 27$ translocations in human lymphomas. Nat Genet 1993:5:66-70.

35 Miki T, Kawamata N, Hirosawa S, et al. Gene involved in the 3q27 translocation associated with B-cell lymphoma, BCL5, encodes a Krupel-like zinc-finger protein. Blood 1994;83:26-32.

$36 \mathrm{Ye} \mathrm{BH}$, Cattoretti G, Shen Q, et al. The BCL-6 proto-oncogene controls germinal-centre formation and the Th2-type inflammation. Nat Genet 1997; 16:161-70.

37 Albagli O, Lantoine D, Quief S, et al. Overexpressed BCL6 (LAZ3) oncoprotein triggers apoptosis, delays $\mathrm{S}$ phase progression and associates with replication foci. Oncogene 1999;18:5063-75.

38 Moller MB, Skjodt K, Mortensen LS, et al. Clinical significance of cyclin-dependent kinase inhibitor p27Kipl expression and proliferation in non-Hodgkin's lymphoma: independent prognostic value of p27Kip 1. Br J Haematol 1999;105:730-6.

39 Sànchez-Beato $\mathrm{M}$, Camacho Fl, Martinez-Montero JC, et al. Anomalous high $\mathrm{p} 27 / \mathrm{KIPl}$ expression in a subset of aggressive B-cell lymphomas is associated with cyclin D3 overexpression. P/27KIP1-cyclin D3 colocalization in tumor cells. Blood 1999;94:765-72.

40 Villuendas R, Sànchez-Beato M, Martinez JC, et al. Loss of p16/INK4 protein expression in non-Hodgkin's lymphomas is a finding associated with tumoral progression. Inactivation of the CDKN2 gene is more frequently due to the novo methylation. Am J Pathol 1998;153:887.

41 Pinyol M, Hernandez L, Martinez A, et al. INK4a/ARF locus alterations in human non-Hodgkin's lymphomas mainly occur in tumors with wild-type p53 gene. Am J Pathol 2000;156:1987-96.

42 Hangaishi A, Ogawa S, Imamura N, et al. Inactivation of multiple tumor-suppressor genes involved in negative regulation of the cell cycle, $\mathrm{MTS} 1 / \mathrm{p} 16 \mathrm{NNK} 4 \mathrm{~A} / \mathrm{CDKN} 2, \mathrm{MTS} 2 / \mathrm{p} 15 \mathrm{INK} 4 \mathrm{~B}$, p53, and Rb genes in primary lymphoid malignancies. Blood 1996;87:4949-58.

43 Pinyol M, Cobo F, Bea S, et al. pl6(INK4a) gene inactivation by deletions, mutations, and hypermethylation is associated with transformed and aggressive variants of non-Hodgkin's lymphomas. Blood 1998;91:2977-84

44 Sanchez-Beato $M$, Saez Al, Navas IC, et al. Overall survival in aggressive B-cell lymphomas is dependent on the accumulation of alteration in p53, pl6, and p27. Am J Pathol 201;159:205-13.

45 Volpe G, Vitolo U, Carbone A, et al. Molecular heterogeneity of B-lineage diffuse large cell lymphoma. Genes Chromosomes Cancer $1996 ; 16: 21$

46 Magrath I. The pathogenesis of Burkitt's lymphoma. Adv Cancer Res 1990;55:133-260.

47 Mateyak MK, Obaya AJ, Sedivy JM. cMyc regulates cyclin D-Cdk4 and -Cdk6 activity but affects cell cycle progression at multiple independent points. Mol Cell Biol 1999;19:4672-83.

48 Bouchard C, Thidke K, Maier A, et al. Direct induction of cyclin D2 by Myc contributes to cell cycle progression and sequestration of $\mathrm{p} 27$. EMBO J 1999;18:5321-33

49 Perez-Roger I, Kim S-H, Griffiths B, et al. Cyclins D1 and D2 mediate Myc induced proliferation via sequestration of $\mathrm{p} 27^{\mathrm{Kipl}}$ and $\mathrm{p} 21^{\mathrm{Cip} 1}$ EMBO J 1999:18:5310-20

50 Bhatia K, Huppi K, Spangler G, et al. Point mutations in the c-MYC transactivation domain are common in Burkitt's lymphoma and mouse plasmacytoma. Nat Genet 1993;5:56.

51 Bhatia K, Spangler G, Gaidano G, et al. Mutations in the coding region of e-myc occur frequently in acquired immunodeficiency syndrome associated lymphomas. Blood 1994;84:883.

52 Papas T, Lautenberg J. Sequence curiosity in v-myc oncogene. Nature 1995;318:237

53 Beijersbergen RL, Hijmans EM, Zhu L, et al. Interaction of e-myc with the pRb-related protein pl07 results in inhibition of c-myc mediated transactivation. EMBO J 1994:13:4080.

54 Gu W, Bhatia K, Magrath IT, et al. Binding and suppression of the c-myc transcriptional activation domain by p107. Science 1994;264:251

55 Preudhomme C, Dervite I, Wattel E, et al. Clinical significance of p53 mutations in newly diagnosed Burkitt's lymphoma and acute lymphoblastic leukemia: a report of 48 cases. J Clin Oncol $1995 ; 13: 812-20$

56 Cinti C, Claudio PP, Howard CM, et al. Genetic alterations disrupting the nuclear localization of the retinoblastoma related gene RB2/p130 in human cell lines and primary tumors. Cancer Res 2000;60:383-9.

57 Cinti C, Leoncini L, Nyongo A, et al. Genetic alterations of the retinoblastoma-related gene RB2/p130 identify different pathogenetic mechanisms in and among Burkitt's lymphoma subtypes. Am J Pathol 2000;156:751-60.

58 Ellwein LB, Purtillo DT. Cellular proliferation and genetic events involved in the genesis of Burkitt lymphoma (BL) in immune compromised patients. Cancer Genet Cytogenet 1992;64:42-8.

59 Hoang AT, Lutterbach B, Lewis BC, et al. A link between increased transforming activity of lymphoma-derived MYC mutant alleles, their defective regulation by $\mathrm{p} 107$, and altered phosphorylation b of the c-myc transactivation domain. Mol Cell Biol 1995; 15:4031-42.

60 Leoncini L, Cossu A, Megha T, et al. Expression of p34cdc2 and cyclins $A$ and $B$ compared to other proliferative features of non-Hodgkin's lymphomas: a multivariate cluster analysis. Int J Cancer 1999;83:203-9.

61 Moller MB, Nielsen O, Pedersen NT. Cyclin D3 expression in non-Hodgkin lymphoma. Correlation with other cell cycle regulators and clinical features. Am J Clin Pathol 2001;115:404-12. 
62 Kiviniemi M, Sauroja I, Rajamaki A, et al. Cell cycle regulators p27 and $\mathrm{pRb}$ in lymphomas: correlation with histology and proliferative activity. $\mathrm{Br}$ J Cancer 2000;83:1161-7.

63 Leoncini L, Bellan C, Cossu A, et al. Retinoblastoma-related p107 and $\mathrm{pRb} 2 / \mathrm{p} 130$ proteins in malignant lymphomas: distinct mechanisms of cell growth control. Clin Cancer Res 1999;5:4065-72.

64 Borgne A, Meijer L. Sequential dephosphorylation of p34cdk2 on Thr-14 and Tyr-15 at the prophase/metaphase transition. J Biol Chem 1996:271:27847-54

65 Kakino S, Sasaki K, Kurose A, et al. Intracellular localization of cyclin B1 during the cell cycle in glioma cells. Cytometry 1996;24:49-54.

66 Li J, Meyer AN, Donoghue DJ. Nuclear localization of cyclin B1 mediates its biological activity and is regulated by phosphorylation. Proc Natl Acad Sci U S A 1997;94:502-7.

67 Peters JM, King RW, Hoog C, et al. Identification of BIME as a subunit of the anaphase-promoting complex. Science 1996;274:1199-201.

68 Jacks T, Weinberg RA. Cell-cycle control and its watchman. Nature 1996;381:643-4.

69 Spina D, Leoncini L, Megha T, et al. Growth patterns of diffuse non-Hodgkin's lymphomas estimated from mitotic and apoptotic indices. Int J Cancer 1997;73:178-83.

70 Leoncini L, Spina D, Close P, et al. Abortive mitosis and nuclear DNA fragmentation in CD30+ large cells of Hodgkin's disease. Leuk Lymphoma 1996;22:119-24.

71 Spina D, Leoncini L, Close P, et al. Growth vs. DNA strand breaks in Hodgkin's disease: impaired proliferative ability of Hodgkin and Reed-Sternberg cells. Int J Cancer 1996;65:1-5.

72 Hall PA. Proliferative activity in Reed-Sternberg cells. Histopathology 1994;24:593-4.

73 Drexler HG. Recent results on the biology of Hodgkin and Reed-Sternberg cells. II. Continuous cell lines. Leuk Lymphoma 1993;9:1-25.

74 Leoncini L, Megha T, Lazzi S, et al. Cellular kinetic differences between Hodgkin's and anaplastic large cell lymphomas: relation to the expression of p34ckc2 and cyclin B-1. Int J Cancer 1998:77:408-14.

75 Leoncini L, Lazzi S, Scano D, et al. Expression of the ALK protein by anaplastic large-cell lymphomas correlates with high proliferative activity. Int J Cancer 2000;86:777-81

76 Iwahara T, Fujimoto J, Wen D, et al. Molecular characterization of ALK a receptor tyrosine kinase expressed specifically in the nervous system. Oncogene 1997; 14:439-49.

77 Morris SW, Naeve C, Mathew P, et al. ALK, the chromosome 2 gene locus altered by $\mathrm{t}(2 ; 5)$ in non-Hodgkin's lymphoma, encodes a novel neural receptor tyrosine kinase that is highly related to leukocyte tyrosine kinase. Oncogene 1997; 14:2175-88.

78 Morris SW, Kirstein MK, Valentine MB, et al. Fusion of a kinase gene ALK, to a nucleolar protein gene, NPM in non-Hodgkin's lymphoma. Science 1994;253:1281-4.

79 Rodriguez GA, Park M. Oncogenic activation of tyrosine kinases. Curr Opin Genet Dev 1994:4:15-24.

80 Bai RY, Dieter P, Peschel C, et al. Nucleophosmin-anaplastic lymphoma kinase of large-cell anaplastic lymphoma is a constitutively active tyrosine kinase that utilizes phospholipase $\mathrm{C}-\gamma$ to mediate its mitogenicity. Mol Cell Biol 1998;18:6951-61.

81 Morris SW, Xue L, Ma Z, et al. ALK+ CD30+ lymphomas: a distinct molecular genetic subtype of non-Hodgkin's lymphoma. Br J Hematol $2001 ; 113: 275-95$

82 Wellmann A, Doseeva V, Butscher W, et al. The activated anaplastic lymphoma kinase increases cellular proliferation and oncogene up-regulation in rat la fibroblasts. FASEB J 1997:11:965-72.

83 Hall PA. Assessing apoptosis: a critical survey. Endocr Relat Cancer $1999 ; 6: 3-6$
84 Leoncini L, Del Vecchio MT, Megha T, et al. Correlations between apoptotic and proliferative indices in malignant non-Hodgkin's lymphomas. Am J Pathol 1993;142:755-63.

85 Symmans WF, Cangiarela JF, Symmans PJ, et al. Apoptotic index from fine needle aspiration cytology as a criterion to predict histologic grade of non-Hodgkin's lymphoma. Acta Cytol 2000;44(2): 194-204.

86 Spina D, Leoncini L, Del Vecchio MT, et al. Low versus high cell turnover in diffusely growing non-Hodgkin's lymphomas. J Pathol 1995; 177:335-341.

87 Reed JC. Apoptosis and cancer. Strategies for integrating programmed cell death. Semin Hematol 2000;37:9-16.

88 Rao L, White E. Bcl-2 and ICE family of apoptotic regulators: making a connection. Curr Opin Genet Dev 1997;7:52-8

89 Korsmeyer SJ. Regulators of cell death. Trends Genet 1995;11:101-5.

90 Reed JC, Zha H, Aime-Sempe C, et al. Structure-function analysis of Bcl-2 family proteins. Regulators of programmed cell death. Adv Exp Med Biol 1996;406:99-112.

91 Farrow SN, Brown R. New members of the Bcl-2 family and their protein partners. Curr Opin Genet Dev 1996;6:45-9.

92 Leoncini L, Del Vecchio MT, Spina D, et al. Presence of the bcl-2 protein and apoptosis in non-Hodgkin lymphomas with diffuse growth pattern. In J Cancer 1995;61:826-30.

93 Hofmann WK, de Vos S, Tsukasaki K, et al. Altered apoptosis pathways in mantle cell lymphoma detected by oligonucleotide microarray. Blood 2001;98:787-94.

94 Chinnaivan AM, Tepper CG, Seldin MF, et al. FADD/MORTI is a common mediator of CD95 Fas/AOP-1 and tumor necrosis factor receptor induced apoptosis. J Biol Chem 1996;271:4961-5.

95 Mueller CM, Scott DW. Distinct molecular mechanisms of Fas resistance in murine B lymphoma cells. Immunology 2000;165:1854-62.

96 Carey GB, Donjerkovic D, Mueller CM, et al. B-cell receptor and Fas-mediated signals for life and death. Immunology 2000;176:105-15.

97 Hennino A, Berard M, Casamayor-Palleja M, et al. Regulation of the Fas death pathway by FLICE-inhibitory protein in primary human $B$ cells. J Immunol 2000; 165:3023-30.

98 Hinz M, Loser P, Mathas S, et al. Constitutive NF-kappa B maintains high expression of a characteristic gene network, including CD40, CD86, and a set of antiapoptotic genes in Hodgkin/Reed-Sternberg cells. Blood $2001 ; 97: 2798-807$

99 Furman RR, Asgary Z, Mascarenhas JO, et al. Modulation of NF-kappa $B$ activity and apoptosis in chronic lymphocytic leukemia B cells. J Immunol 2000; 164:2200-6

100 Dierlamm J, Baens M, Wlodarska I, et al. The apoptosis inhibitor gene AP12 and a novel $18 q$ gene, MLT, are recurrently rearranged in the t $11 ; 18$ ) (q21,q21) associated with mucosa-associated lymphoid tissue lymphoma. Blood 1999;93:3601-9.

101 Adida C, Haioun C, Gaulard P, et al. Prognostic significance of survivin expression in diffuse large B-cell lymphomas. Blood 2000;96:1921-5.

102 Wensing B, Farrel P. Regulation of cell growth and death by Epstein-Bar virus. Microbes Infect 2000;2:77-84.

103 Spina D, Leoncini L, Megha T, et al. Cellular kinetic and phenotypic heterogeneity in and among Burkitt's and Burkitt-like lymphomas. J Patho 1997; 182: 145-50.

104 Ruf IK, Rhyne PW, Yang H, et al. Epstein-Barr virus regulates c-MYC, apoptosis, and tumorigenicity in Burkitt lymphoma. Mol Cell Biol 1999; 19:1651-60.

105 D'Souza B, Rowe M, Walls D. The bfl- 1 gene is transcriptionally upregulated by the Epstein-Barr virus LMP1, and its expression promotes the survival of a Burkitt's lymphoma cell line. J Virol 2000;74:6652-8.

106 Claudio PP, Caputi M, Giordano A. The RB2/p130 gene: the latest weapon in the war against lung cancer? Clin Cancer Res 2000;6:754-64 